\title{
Where and how are Brazilian dental students using Glass Ionomer Cement?
}

\begin{abstract}
Marina Sousa Azevedo(a)
Daniela Vilas Boas(b)

Flávio Fernando Demarco(c) Ana Regina Romano(a)
\end{abstract}

(a) Department of Social and Preventive Dentistry, School of Dentistry, Federal University of Pelotas, Pelotas, RS, Brazil.

(b) School of Education, Federal University of Pelotas, Pelotas, RS, Brazil.

(c) Department of Operative Dentistry, School of Dentistry, Federal University of Pelotas, Pelotas, RS, Brazil.

\section{Corresponding author:}

Marina Sousa Azevedo

Rua Carlos Gomes, 23, Três Vendas

Pelotas - RS - Brasil

CEP: 96055-450

E-mail:marinasazevedo@hotmail.com

Received for publication on Jun 10, 2010 Accepted for publication on Aug 05, 2010

\begin{abstract}
Glass Ionomer Cements (GICs) have a wide range of uses in Dentistry, and the manipulation technique used can influence the results obtained. This study aimed at assessing the knowledge held by Dental School students from a city in Southern Brazil regarding the use of GIC, and the clinical technique chosen for its use and its applications. A structured questionnaire was applied to 60 advanced dental students. Descriptive statistics was used to analyze the quantitative data. All students had already used the material. Regarding the purpose for which the material was used, all students $(100 \%)$ had used it as a dental cavity liner, $83.3 \%$ had used it as a temporary restorative material after endodontic treatment, and $73.3 \%$ had used it as a permanent restoration in primary teeth. Regarding the clinical technique used, $86.7 \%$ said that they insert the material while it still has a shiny surface, $33 \%$ said that they finish and polish the restoration in a following session, and only $28.3 \%$ said that they apply a surface protection immediately after the restoration is placed. Although students generally seem to be acquainted with the fundamental knowledge and main techniques involved in GIC use, they occasionally fail to follow all the technical steps required during clinical application, which may affect treatment outcome. Therefore, professors should stress that all the clinical procedures required during GIC application must be followed strictly to improve the performance of this material.
\end{abstract}

Descriptors: Knowledge; Students, Dental; Glass Ionomer Cements; Education, Dental.

\section{Introduction}

Glass Ionomer Cements (GICs) were developed in the 1970s by the English researchers Wilson and Kent, ${ }^{1}$ and have evolved constantly since then. These cements exhibit clinical advantages, such as continuous fluoride release throughout the life of the restoration, ${ }^{2}$ which gives the material anticariogenic properties, ${ }^{3}$ adhesion to both enamel and dentin, and a low coefficient of thermal expansion, similar to that of the dental structure. However, Glass Ionomer Cements present some negative properties, such as low cohesive resistance and low wear resistance, factors limiting their use as filling materials to areas subject to low masticatory stresses. ${ }^{4}$

They are indicated not only as restorative materials, in both deciduous and permanent teeth, but also as cavity liners and luting agents for the cementation of bands, brackets, crowns and posts. ${ }^{5}$ 
One of the most critical aspects related to the clinical performance of GIC is the way they are manipulated and the technique employed. Variations in these aspects can modify not only the final consistency of the material, but also its mechanical properties, ${ }^{6}$ which may interfere in the expected outcome.

Although it is expected that students should be aware of the biological, chemical and physical principles involved in GIC application techniques, there have been some doubts as to whether dental students are fully qualified to use these dental materials properly. ${ }^{7}$ Surveys with dental students are important tools to assess how well they know the topics covered in dental course curricula. ${ }^{8}$ Thus, the aim of this study was to assess how well the Dental School students from a city in Southern Brazil knew the techniques employed in using Glass Ionomer Cement as restorative, luting and lining materials.

\section{Material and Methods}

This study was reviewed and approved by the institutional Ethics Committee (protocol 067/2008). The students were informed of the objectives of the study, and a questionnaire was applied after obtaining their written consent.

The questionnaire comprised 35 questions grouped in 5 main areas:

- General information about the population (age, gender, and which semester they were attending)

- Frequency and use of Glass Ionomer Cement in different areas of Dentistry

- Kind of material used and preferences

- Clinical use of Glass Ionomer Cement

- Technique employed

The questionnaire was applied by 4 previously trained interviewers (May 2009) and answered by advanced students (from the $8^{\text {th }}$ and $9^{\text {th }}$ semesters).

Descriptive statistics was used to analyze the quantitative data, and keywords and concepts were used to analyze the open questions.

\section{Results}

Of the 77 regularly enrolled students in the $8^{\text {th }}$ and $9^{\text {th }}$ semesters of Dental School, 17 refused to answer the questionnaire. Fifty-eight percent of the respondents were enrolled in the $8^{\text {th }}$ semester, and $41.7 \%$, in the $9^{\text {th }}$ semester. The average age of the students was 24.2 years; $38.3 \%$ of them were male and $61.7 \%$ were female.

All students reported having already used GIC at least once in their clinical practice (Table 1).

When asked in which areas they had already used GIC, the only area that was not mentioned was surgery. The great majority reported having used the material in Restorative Dentistry $(100 \%)$ and Pediatric Dentistry (96.7\%).

Regarding the type of material, conventional Glass Ionomer Cement was the most widely used $(100 \%)$, mainly for restorative purposes $(93.3 \%)$, followed by luting $(80 \%)$ and cavity lining applications (38.3\%). Light-cured GIC was used by $60 \%$ of the respondents, resin-modified GIC was used by $58.3 \%$ of the respondents, and metal-reinforced GIC was used by one student.

Seventy percent of the students said that they did not have any preferences regarding GIC type. Most students who stated their preferences mentioned resin-modified GIC as their material of choice.

It was observed that $98.4 \%$ of the students intended to use these materials in their future clinical practice. When asked about the reasons for this, most mentioned that it was because of the characteristics of the material, especially:

- Biocompatibility with dental tissues

- Easy use

- Cost effectiveness

- Effective use as a cavity liner

Table 2 shows the clinical uses of GIC reported by the dental students.

Most students (93.3\%) said that they followed the manufacturer's instructions regarding the recommended powder/liquid ratio to be used during

Table 1 - Frequency of use of Glass lonomer Cement by students attending the Dental School, Federal University of Pelotas, RS, Brazil $(n=60)$

\begin{tabular}{c|c}
\hline Frequency of use & \% Students \\
\hline 5 times or less & 1.7 \\
\hline From 5-10 times & 8.3 \\
\hline More than 10 times & 90 \\
\hline
\end{tabular}


Table 2 - Percentage of the clinical uses of Glass lonomer Cement reported by the dental students.

\begin{tabular}{l|c}
\hline \multicolumn{1}{c|}{ Use of Glass lonomer Cement } & \% Students \\
\hline Cavity liner & 100.0 \\
\hline $\begin{array}{l}\text { Temporary restorative material } \\
\text { after endodontic treatment }\end{array}$ & 83.3 \\
\hline Permanent restoration in primary teeth & 73.3 \\
\hline $\begin{array}{l}\text { Class V restoration in permanent teeth } \\
\text { (erosion, abrasion, abfraction) }\end{array}$ & 66.7 \\
\hline Atraumatic restorative treatment (ART) & 51.7 \\
\hline Class V restoration in permanent teeth (caries) & 48.3 \\
\hline Fissure sealant & 36.7 \\
\hline Cervical barrier in bleaching procedures & 35.0 \\
\hline Class I conservative restoration in permanent teeth & 25 \\
\hline Class II tunnel restoration in permanent teeth & 21.7 \\
\hline Prosthesis cementation & 18.3 \\
\hline Core build-up & 16.7 \\
\hline Class II restoration in permanent teeth & 15 \\
\hline Orthodontic band cementation & 13.3 \\
\hline Furcation perforation treatment & 8.3 \\
\hline Restoration in cusp area in permanent teeth & 8.3 \\
\hline Class III restoration in permanent teeth & 4 \\
\hline Class IV restoration in permanent teeth & 3 \\
\hline Retrograde filling material in periapical surgery & 1.7 \\
\hline
\end{tabular}

the clinical procedure. In addition, $86.7 \%$ reported that they inserted the cement when it still presented a shiny surface, $33 \%$ finished and polished the restoration in a following session, and only $28.3 \%$ applied an immediate surface protection after restoration.

\section{Discussion}

The criterion used to select the students for this survey was how advanced they were in their undergraduate course curriculum. By the time students have gained experience in the clinical areas where GIC could be used, it is expected that they would also have had dental materials classes ( $4^{\text {th }}$ semester), where they are supposed to receive the necessary knowledge regarding GIC. Therefore, we assessed whether the basic knowledge received during dental materials classes was still in the students' minds when using GIC clinically. Since these materials are very sensitive regarding the techniques of manipulation and application used, dental students should be fully aware of these techniques in order to use the materials effectively, hence the importance of applying a questionnaire to measure how well students know about GIC use.

Our results were limited to a single dental school, and we were aware that our findings could not be generalized since each school follows a different curriculum and uses different teaching methods. The continuous development of GIC since its introduction has allowed a wider range of uses in clinical dentistry. In this study, $90 \%$ of the students reported having used these materials more than 10 times, indicating that they have used them frequently. Students have used GIC in different clinical areas, and all of them reported having used it in Restorative Dentistry. This could explain the several applications of GIC in this area, where it can be used as cavity liner, temporary restorative material, permanent class $\mathrm{V}$ restoration, and for the provisional cementation of indirect restorations.

GIC was also largely applied $(96.7 \%)$ in Pediatric Dentistry, probably because resin-modified and conventional GICs have proven to be durable and reliable materials for Class I and II restorations. ResinModified Glass Ionomer Cements (RMGIC) have also proven to be suitable materials for Class III and Class $\mathrm{V}$ restorations in primary teeth. ${ }^{4,9}$ However, according to Qvist et al., ${ }^{10}$ Class III/V restorations should be made in conventional GIC, since it boosts the longevity of restorations, whereas RMGIC should be used preferably for Class II restorations in primary dentition. However, there is a study that assessed the need for prospective randomized clinical trials lasting at least 5 years to determine correctly the success rate of Class II restorations in primary molars. ${ }^{11}$ GIC is an alternative to silver amalgam and resin-based composite for primary teeth restorations, with the advantages of being less technically demanding ${ }^{12}$ and providing fluoride release that is highly important for high-risk patients.

Furthermore, this material can be used as a pit and fissure sealant to prevent occlusal caries; an in situ study has also shown that sealing with glass ionomer cement made the enamel of pits and fissures 
more resistant by increasing its Knoop hardness. ${ }^{13}$ Although resin composite is more commonly used as a sealant, both materials appear to be equally suitable for clinical application as a fissure sealant material. ${ }^{14,15}$ GICs have been employed in primary teeth as a "permanent" restorative material because these teeth will be later replaced by the permanent ones. Nevertheless, in permanent teeth, restorations made with resin-modified GIC, which has better mechanical properties than those of conventional GIC, do not seem to perform well in terms of marginal characteristics, surface properties and color stability over time. ${ }^{16}$ Its relatively poor mechanical properties indicate the use of GIC as a permanent restorative material only in low stress situations. ${ }^{17}$ This could explain why such a high rate of students $(83.3 \%)$ reported using it as a temporary restorative material in permanent teeth.

Another use of GIC widely reported by the students was in Class V restorations (66.7\%). Clinical studies have shown that resin-modified GIC has an acceptable performance in Class $\mathrm{V}$ cavities. ${ }^{18} \mathrm{In}$ terestingly, however, the number of respondents that used RMGIC (58.3\%) for Class V cavities was lower than the number that reported using conventional GIC for this application. Based on this data, we may infer that students may not be choosing the best GIC type to achieve the expected performance, which may consequently lead to a reduced clinical service of Class $\mathrm{V}$ restorations when conventional GIC is used.

GIC is the material used for Atraumatic Restorative Treatment (ART) because it is self-curing, has adhesive properties and is biocompatible. Although ART was developed to be used in the less industrialized parts of the world, this procedure has been accepted as part of a minimal intervention philosophy in developed countries, proving to be an appropriate option for the treatment of primary teeth. ${ }^{19}$ This may explain why more than $50 \%$ of the students reported applying GIC for the ART technique.

Class II tunnel restorations preserve the anatomical marginal ridge and minimize the loss of healthy tooth structure adjacent to the carious lesion. However, the main disadvantage of the tunnel technique has been the difficulty in completely removing den- tin caries. ${ }^{20} \mathrm{GIC}$ is thus the material of choice for these cavities because of its anticariogenic properties, which may contribute to remineralization.

Few students mentioned the use of GIC in orthodontic band cementation. This procedure is rarely used in the school surveyed since only preventive orthodontics is employed and, in many cases, only removable appliances are used. A systematic review that evaluated the effectiveness of the adhesives used to attach bands to teeth during fixed appliance treatment concluded that there is insufficient high quality evidence to indicate the most effective adhesive for attaching orthodontic bands. ${ }^{21}$ However, the advantages of choosing GIC are its ability to bond to enamel and stainless steel, and its ability to leach fluoride.

It was also found that conventional GICs were more frequently used than RMGICs $(100 \%$ and $58.3 \%$, respectively). Probably, the main reason for the lower application of RMGICs is their significantly higher cost as compared to that of conventional GICs. Conventional GIC also presents better biocompatibility, which could account for its broader application. RMGIC has HEMA (2-hydroxethyl methacrylate) in its formulation, meaning that the release of this monomer and its diffusion through the dentin may cause toxic effects on the pulp tissue, ${ }^{22}$ thus restricting the use of RMGIC in some cases. Although RMGICs offer some advantages over conventional GICs, such as increased resistance and longer working time, conventional GICs may also be used in many of the procedures mentioned above. Perhaps, this is the reason why $70 \%$ of the students did not report any preference regarding cement types, although it could be expected that students from more advanced semesters would be able to select the best material for each procedure.

It should be pointed out that all the students had already used Glass Ionomer Cement as cavity liners, probably because the use of this cement as an underfilling material considerably reduces the required resin composite bulk, thus reducing the total composite polymerization shrinkage, which improves marginal adaptation. ${ }^{23}$

More than $90 \%$ (93.3\%) of the responders mentioned that they followed the manufacturers' recom- 
mendations regarding the powder/liquid ratio used and that they inserted the material when it still had a shiny surface $(86.7 \%)$. According to Behr et al. ${ }^{6}$ mistakes during GIC manipulation can reduce the wear resistance and the hardness of the material, reinforcing the importance of following the manufacturers' instructions, mainly because the powder/ liquid ratio varies significantly not only between different manufacturers, but also according to the purpose of the application (lining, luting or restorative). Inserting the material when it is still shiny is another important factor, since GIC bonds chemically to the tooth substrate, and the shiny surface indicates the presence of available liquid, which contains carboxyl radicals that will bind to calcium ions, dentin and cement, promoting adherence to the tooth. ${ }^{17}$

As regards surface protection, $71.7 \%$ of the students said that it was not necessary to protect the surface of GIC restorations with coatings. GIC is highly sensitive to humidity during its chemical setting reaction (first 24 hours). If newly-placed glass ionomer restorations are exposed to water during this period there will be water sorption, ${ }^{24}$ surface erosion $^{25}$ and loss of translucency, which negatively affect the clinical performance of the material. ${ }^{12}$ Thus, surface protection is indicated, and some products, such as nail varnish, are effective for this purpose at a low cost. ${ }^{26,27}$ During the dental materials classes of their regular curriculum, students are taught that the surface needs to remain protected, and they should therefore be aware of this.

The period observed before finishing and polishing GIC restorations is a factor that may influence

\section{References}

1. Wilson AD, Kent BE. A new translucent cement for dentistry. A glass ionomer cement. Br Dent J. 1972 Feb 15;132(4):133-5.

2. Garcez RMVB, Buzalaf MAR, Araújo PA. Fluoride release of six restorative materials in water and $\mathrm{pH}$-cycling solutions. $\mathrm{J}$ Appl Oral Sci. 2007 Oct;15(5):406-11.

3. Wiegand A, Buchalla W, Attin T. Review on fluoride-releasing restorative materials-Fluoride release and uptake characteristics, antibacterial activity and influence on caries formation. Dent Mater. 2007 Mar;23(3):343-62. Epub 2006 Apr 17. their surface topography and sealability. Polishing after 24 hours showed more acceptable surface topography and less gap incidence compared to polishing immediately afterwards; ${ }^{28,29}$ however few students $(33 \%)$ reported observing the prescribed period of time before conducting polishing procedures.

This data highlights the importance of not only teaching about GICs, but also reminding students constantly about the need to follow the protocols and instructions for their correct manipulation and use.

\section{Conclusion}

The overall results of this study demonstrate that students seem to be acquainted with the types, properties, uses, and technical procedures regarding GICs. However, in some situations, students do not follow some clinical procedures that may affect the properties of the materials and the treatment outcomes. Therefore, dental instructors should constantly remind their students of how important it is to follow strictly the correct procedures for use of these materials, thus making them better qualified to choose the best technique to guarantee the best performance of the product and, consequently, the best outcomes for their patients.

\section{Acknowledgments}

The authors would like to thank students Leticia Brancher, Fernando Silva, Paula Silva, Marcela Yurgel and Jorge Pereira Jr. for their assistance in collecting the data.

4. Croll TP, Bar-Zion Y, Segura A, Donly KJ. Clinical performance of resin-modified glass ionomer cement restorations in primary teeth. J Am Dent Assoc. 2001 Aug;132(8):1110-6.

5. Pegoraro TA, da Silva NRFA, Carvalho RM. Cements for use in esthetic dentistry. Dent Clin North Am. 2007 Apr;51(2):453-71.

6. Behr M, Rosentritt M, Loher H, Kolbeck C, Trempler C, Stemplinger B, et al. Changes of cement properties caused by mixing errors: The therapeutic range of different cement types. Dent Mater. 2008 Sep;24(9):1187-93. Epub 2008 Mar 26. 
7. Ueda M, Mine A, DE Munck J, Hakogi T, VAN Meerbeek B, Kuboki T. The effect of clinical experience on dentine bonding effectiveness: students versus trained dentists. J Oral Rehabil. 2010 Sep;37(9):653-7. Epub 2010 May 21.

8. Cardall WR, Rowan RC, Bay C. Dental education from the students' perspective: curriculum and climate. J Dent Educ. 2008 May;72(5):600-9.

9. Daou MH, Tavernier B, Meyer JM. Two-year clinical evaluation of three restorative materials in primary molars. J Clin Pediatr Dent. 2009 Fall;34(1):53-8.

10. Qvist V, Manscher E, Teglers PT. Resin-modified and conventional glass ionomer restorations in primary teeth: 8 -year results. J Dent. 2004 May;32(4):285-94.

11. Toh SL, Messer LB. Evidence-based assessment of toothcolored restorations in proximal lesions of primary molars. Pediatr Dent. 2007 Jan-Feb;29(1):8-15.

12. Davidson CL. Advances in glass-ionomer cements. J Appl Oral Sci. 2006;14 Suppl:3-9.

13. Amaral MT, Guedes-Pinto AC, Chevitarese O. Effects of a glass-ionomer cement on the remineralization of occlusal caries - an in situ study. Braz Oral Res. 2006 Apr-Jun;20(2):91-6.

14. Yengopal V, Mickenautsch S, Bezerra AC, Leal SC. Cariespreventive effect of glass ionomer and resin-based fissure sealants on permanent teeth: a meta analysis. J Oral Sci. 2009 Sep;51(3):373-82.

15. Niederman R. Glass ionomer and resin-based fissure sealants - equally effective? Evid Based Dent. 2010;11(1):10.

16. Sidhu SK. Clinical evaluations of resin-modified glass-ionomer restorations. Dent Mater. 2010 Jan;26(1):7-12.

17. Tyas MJ. Clinical evaluation of glass-ionomer Cement restorations. J Appl Oral Sci. 2006;14 Suppl:10-3.

18. Loguercio AD, Reis A, Barbosa AN, Roulet JF. Five-year double-blind randomized clinical evaluation of a resin-modified glass ionomer and a polyacid-modified resin in noncarious cervical lesions. J Adhes Dent. 2003 Winter;5(4):323-32.

19. Honkala E, Behbehani J, Ibricevic H, Kerosuo E, Al-Jame G. The atraumatic restorative treatment (ART) approach to re- storing primary teeth in a standard dental clinic. Int J Paediat Dent. 2003 May;13(3):172-9.

20. Pilebro C, van Dijken JWV, Stenberg R. Durability of tunnel restorations in general practice: a three-year multicenter study. Acta Odontol Scand. 1999 Feb;57(1):35-9.

21. Millett DT, Glenny AM, Mattick CR, Hickman J, Mandall NA. Adhesives for fixed orthodontic bands. Cochrane Database Syst Rev. 2007 Apr 18;(2):CD004485.

22. Nicholson JW, Czarnecka B. The biocompatibility of resinmodified glass-ionomer cements for dentistry. Dent Mater. 2008 Dec;24(12):1702-8. Epub 2008 Jun 9.

23. Friedl KH, Schmalz G, Hiller KA, Mortazavi F. Marginal adaptation of composite restorations versus hybrid ionomer/ composite sandwich restorations. Oper Dent. 1997 JanFeb;22(1):21-9.

24. Karaoglanoglu S, Akgül N, Özdabak HN, Akgül HM. Effectiveness of surface protection for glass-ionomer, resin-modified glass-ionomer and polyacid-modified composite resins. Dent Mater J. 2009 Jan;28(1):96-101.

25. McLean JW. Glass ionomer cements. Br Dent J. 1988 May 7;164(9):293-300.

26. Brito CR, Velasco LG, Bonini GA, Imparato JC, Raggio DP. Glass ionomer cement hardness after different materials for surface protection. J Biomed Mater Res A. 2010 Apr;93(1):243-6.

27. ShintomeI LK, NagayassuI MP, NicolóII RD, MyakiII SI. Microhardness of glass ionomer cements indicated for the ART technique according to surface protection treatment and storage time. Braz Oral Res. 2009 Oct-Dec;23(4):439-45.

28. Amin A-el-H M, Farid MR. Finishing of glass-ionomer cement (SEM study). Egypt Dent J. 1994 Oct;40(4):903-8.

29. Irie M, Maruo Y, Nishigawa G, Suzuki K, Watts DC. Class I gap-formation in highly-viscous glass-ionomer restorations: delayed vs. immediate polishing. Oper Dent. 2008 MarApr;33(2):196-202. 